\title{
Analysing the scientific conference presentation (CP), A methodological overview of a multimodal genre
}

Shirley Carter-Thomas and Elizabeth Rowley-Jolivet

\section{(2) OpenEdition}

\section{Journals}

Electronic version

URL: http://journals.openedition.org/asp/1295

DOI: $10.4000 /$ asp. 1295

ISBN: 978-2-8218-0392-3

ISSN: $2108-6354$

Publisher

Groupe d'étude et de recherche en anglais de spécialité

\section{Printed version}

Date of publication: 1 May 2003

Number of pages: $59-72$

ISSN: 1246-8185

\section{Electronic reference}

Shirley Carter-Thomas and Elizabeth Rowley-Jolivet, « Analysing the scientific conference presentation (CP), A methodological overview of a multimodal genre », ASp [Online], 39-40 | 2003, Online since 10 May 2010, connection on 03 July 2020. URL : http://journals.openedition.org/asp/ 1295 ; DOI : https://doi.org/10.4000/asp.1295

This text was automatically generated on 3 July 2020.

Tous droits réservés 


\title{
Analysing the scientific conference presentation (CP), A methodological overview of a multimodal genre
}

\author{
Shirley Carter-Thomas and Elizabeth Rowley-Jolivet
}

\section{Introduction}

1 In ESP, knowledge of written academic genres is now well advanced. Numerous ESP analysts have devoted extensive study to the functioning and organisation of written scientific texts, of which the research article (RA), is the most obvious example (Swales 1990; Dudley-Evans 1994; Candlin \& Hyland 1999; Hyland 2000, Trosborg 2000). Our knowledge of spoken academic genres is however much less complete and much remains to be done in terms of generic characterisation, both in distinguishing different types of spoken academic communication (seminars, conference presentations, keynote addresses, didactic lectures) and in characterising these across disciplines.

2 Among the various spoken genres that the academic researcher needs to master, a key one is the conference presentation genre (CP). Conference presentations play an essential role in the life of research communities (Rowley-Jolivet 1999), but due to this relative lack of interest in spoken academic discourse, specific work on this important genre is only just beginning to appear (Ventola et al. 2002; Simpson \& Swales 2001; Swales, in press). If ESP researchers have until recently concentrated on written academic genres at the expense of spoken ones is it however because of the relative difficulties of acquiring spoken corpora or is it because these genres are less easily apprehended? Can the conference presentation be analysed and deconstructed in the same way as a written scientific text?

In this article we will consider three different approaches that can contribute towards characterising the $\mathrm{CP}$ in science. We will consider the advantages and limitations of the three approaches examined, and highlight some of the methodological issues involved. 
The first approach considered is that of a more microscopic bottom-up analysis, focusing primarily on the recurrent syntactic features of the CP. Such an approach provides us with useful information on the relation between generic features, communicative context and language choices at a local level; it does not however enable us to gain an insight into the higher level structural organisation of the conference presentation. In a second approach we therefore adopt a more top-down macroscopic view, examining to what extent move analysis can be used to explore the rhetorical structure of the $\mathrm{CP}$. We present a move analysis model which we feel can be usefully applied to analysing $\mathrm{CP}$ introductions. This approach though, in the same way as the bottom-up syntactic analysis, places the emphasis on the verbal realisation of the textual product and does not take into account the multimodal nature of the scientific conference presentation. To capture the generic features of the conference presentation it would seem necessary to consider all the semiotic resources used, and not only language. In a third stage we therefore investigate the methodological issues involved in analysing the visual channel of communication, an essential but until now little studied aspect of this multimodal genre.

4 The spoken data used for the study comprise 44 15-20 minute presentations given at international scientific conferences in three fields (geology, medicine, and physics) by native speakers. The presentations were recorded on video and then transcribed. A smaller comparative corpus composed of 9 of the physics presentations and the 9 corresponding articles published in the book of proceedings of the physics conference (same authors, topics, and event) was also collected, to enable comparison between the presentations and proceedings articles $(\mathrm{PA})^{1}$.

\section{The conference presentation genre}

5 As a framework to the methodological overview proposed we will begin by considering some of the essential contextual features and functions of the $\mathrm{CP}$. It is now widely accepted by most genre analysts in ESP that a genre is to be envisaged as a communicative event, which occurs in a particular socio-cultural context and which has a specific communicative function (Swales 1990). Genres however are not fixed static events and need to be positioned in relation to one another, as within a given discourse community there are a range of recognised genres, which are mutually defining and constitute a system (Fairclough 1992: 126). In order to trace the boundaries of the scientific conference presentation genre it is useful to make comparisons with agnate genres, and a brief comparison with the conference proceedings article will thus provide a relevant starting point.

6 The $\mathrm{CP}$ and PA are both operated by the same discourse community and can be considered as research process genres. There is also a certain shared content and intellectual tradition, which manifests itself in the high information load conveyed. In both cases the public is also composed of specialists and shared knowledge is extensive. However the constraints governing the two events are radically different and this has an obvious impact on the precise choice of content, structure, language and semiotic resources brought into play. Among the contextual features which distinguish the two genres, three appear particularly significant:

1. The CP is, even if semi-prepared and/or rehearsed, a live event in real-time. Speakers have to adapt the high-density informational content to this constraint. This has important 
implications for production and comprehension. The complex noun groups and nominalisations, characteristic of the RA or corresponding PA are ill suited for this reason in the CP. Time is also a limiting factor. In a ten or fifteen minute presentation the content transmitted will be far less than in a corresponding article.

2. The purpose of scientific research communication, whether spoken or written, is not only informative but also rhetorical in that it aims to persuade. The relationship with audience or readership is however very different in the two cases. In the article the authors will usually adopt a detached stance, impressing upon the readers their prudence and objectivity so as not to limit the scientific validity of the propositions. In the $\mathrm{CP}$, on the contrary, as the audience is physically present in the auditorium, it is necessary to set up a feeling of connivance. Too detached a monologue would be ill-suited to the communicative context and appropriate interpersonal strategies are important.

3. The semiotic modes employed are also different in the two cases. The CP is an audio-visual presentation and makes use not only of linguistic semiotic means, but also mathematical and visual semiotics. While the main channel of communication is arguably the spoken one, the importance of the visual channel should not be underestimated. In scientific conferences a large number of visuals (slides, transparencies or Powerpoint displays) accompany the speaker's discourse, and audiences are expected to listen and read simultaneously. One of the tasks of the speaker is to integrate this visual information into the verbal commentary.

7 All of the above features can be expected to have an impact on the language choices visible in the textual product. In order to examine these choices we will first consider a bottom up microscopic approach, examining certain discourse surface features with regard to their textual functions.

\section{Microscopic syntactic approach}

In a previous study (Carter-Thomas \& Rowley-Jolivet 2001) this approach was used to make a comparative analysis of some of the preferred syntactic patterns used in the CP as opposed to the written PA. Within one specific discipline, physics, we analysed a strictly parallel corpus of conference presentations and proceedings articles produced on the occasion of the same conference by a group of NS researchers. The aim of this study was to pinpoint some recurrent syntactic patterns particular to each conference genre and to evaluate the influence of modal and contextual factors on the syntactic choices made.

We situated the analysis within an information structure framework, evaluating the way speakers and writers manipulated syntax depending on the informational weight of clauses and of their potential impact upon the receiver. Thanks to this framework we were able to relate the syntactic choices made to the precise conditions of production and reception in the discourse. Certain syntactic devices, such as existential there, inversion and pseudo-clefts, which occurred infrequently if at all in the PA, were found to provide extremely effective and relevant information packaging strategies in the context of the CP. On the contrary, other syntactic patterns, such as the passive and structures involving extraposition, were seen only to be really characteristic of the written genre. They were used sparingly in the corresponding $\mathrm{CP}$, as they did not provide packaging strategies suited to the requirements of spoken scientific discourse.

The relative absence of passive constructions in the CP can for example be directly related to certain features of the live communicative event. Demands on the real-time 
processing of information mean that the complex nominal group and passive combination frequent in the article would be extremely difficult to produce and process in the live $\mathrm{CP}$ environment. The following example is an illustration:

The coupling impedance between the slow space charge wave on the electron beam and the surface harmonics of the backward TMO1 can be modified (A14) ${ }^{2}$

11 Moreover, the traditional impersonality and distance afforded by the passive are not as relevant in an oral presentation, as speakers adopt a more direct approach when addressing a live audience. The low proportion of passive constructions was seen to be correlated with a correspondingly high proportion of personal pronoun (animate) syntactic subjects followed by an active verb, with speakers tending to express actions and opinions congruently and taking personal responsibility for their decisions and interpretations.

12 Considerations relating to author responsibility can also explain why structures involving extraposition are less frequently found in the CP. In their writing scientists often use extraposition as a hedging tactic, as it provides a grammatical framework for expressing stance or evaluation while at the same time, like the passive, respecting the impersonal tone commonly found in research articles. In the $\mathrm{CP}$, however, as speakers express their evaluation and comments far more openly, the recourse to hedging is less necessary, as the following parallel examples illustrate:

\begin{tabular}{|l|l|}
\hline Article & Presentation \\
\hline It is possible to define & We can define \\
\hline It can be implied that & We know \\
\hline
\end{tabular}

13 The speaker's choice to orient such clauses as these around personal themes in the CP makes the presentation much livelier and creates overall very different interpersonal relations to those of the article.

14 The conference presentation environment also requires the use of certain syntactic patterns which are little used in scientific writing. Existential constructions, for example, were found to have an important discourse organising role in the $\mathrm{CP}$, serving frequently as enumeration or segmentation devices, a role fulfilled to a great extent by typographical conventions in the article. The greater frequency of structures involving inversion in the $\mathrm{CP}$ was also seen to be related to the specific communicative context. Inversion was a favoured strategy employed by conference speakers for integrating the visual and verbal channels of communication. Using inversion enables the speaker to draw the audience's attention to a visual display, before commenting verbally on it, thus guiding the audience's interpretation of this visual information: On this axis is electric field (P2).

15 Pseudo-clefts, which practically never occur in the scientific article, were also found to play a crucial role in the CP. They serve to generally slow down the discourse flow, segmenting the discourse into manageable chunks and signalling the salience of particular items of information. The regular pseudo-cleft (or Wh-cleft) also enables presenters, through a questioning process implied by the Wh element, to highlight the originality or novelty of their research in a suitably interactive way: 
What this work has shown is that you can describe the FEL with just two parameters

(P12)

What we decided to do was to try to generate a glow-discharge plasma (P8)

$$
\text { ha }
$$
characteristics, communicative context and language choices at the local level. The
bottom-up approach detailed above has made it possible to pinpoint and evaluate several syntactic features characteristic of the CP genre and to gain valuable insight into the articulation between syntactic choices and their rhetorical appropriacy (Rowley-Jolivet \& Carter-Thomas forthcoming). However, such an approach also has a number of limitations. Firstly, language is not the only semiotic through which meaning is construed. The emphasis on formal linguistic features masks the interplay of the other semiotics, and namely the visual semiotic which plays a vital role in the multimodal CP. Secondly, a microscopic approach, operating primarily at sentence level cannot provide information about the structural organisation of the $\mathrm{CP}$ at a higher level. In order to have a more complete understanding of the generic functioning of the $\mathrm{CP}$ and its communicative purpose, it is important to adopt a more macroscopic viewpoint and address the question of the specific rhetorical structure of the discourse.

\section{Rhetorical approach}

\subsection{Issues involved}

A more macroscopic approach to genre analysis, and one that has been closely associated with genre analysis in ESP since the 1980s, is the rhetorical approach, based on the identification of schemata or recurrent moves. The principal aim of a move analysis model is to gain insight into the communicative purpose of a discourse genre and into its specific rhetorical structure as it moves towards this purpose. Move analysis in ESP has however to the best of our knowledge been applied almost exclusively to written discourse, with innumerable studies of moves in various written academic genres in the wake of John Swales' initial 4-move model (1981) and the revised (1990) Create A Research Space (or CARS) model of the introductions in research Our analysis of the differing frequencies of different syntactic patterns in the CP and PA
has enabled us to obtain useful information on the relation between generic 
articles (e.g. Hopkins 1985; Peng 1987; Dudley-Evans 1994; Brett 1994; Nwogu 1997; Samraj 2002). From a methodological viewpoint it was thus important to establish whether move analysis could indeed be usefully applied to a spoken academic genre. Would it be possible to attribute a clear rhetorical movement to the CP in the same way as has been done for the RA? Would existing move models initially developed for written discourse prove to be applicable?

We decided to concentrate on the introduction sections to the $\mathrm{CP}$, firstly so as to enable comparison with the Swalesian CARS model and secondly because of the undeniably important rhetorical role of introductions in positioning academic research. An analysis was therefore undertaken of the Introductions to 44 conference presentations in 3 scientific fields.

A major methodological problem was however encountered right at the outset: how can the cut-off points of even the principal sections of the CP be identified introduction, methods, discussion, etc.? These are clearly materialised in the RA, but not in a spoken monologue. The introduction is probably the easiest section to tackle as the beginning is easily identified. Deciding where an introduction finishes however is less apparent, as speakers very rarely use structuring metadiscourse markers to signal the transition (Thompson 2003). We therefore made use of a variety of clues: the content itself, various frame markers such as Well, So and structures such as pseudoclefts (So what we decided to do was...). We also studied research articles in the same speciality and consulted specialist informants when necessary. Another extremely important clue was the visuals shown during the presentation, as these, either by their titles or by a shift in the type of visual, often clearly indicate the beginning of a new section. A dual-rating system was also used throughout the whole process until agreement between the two analysts was reached.

Once the $44 \mathrm{CP}$ introductions had been satisfactorily delimited, the question remained as to whether existing models of move structure would be applicable to their analysis. The RA introductions analysed by Swales (1990), in that they were also a research process genre, produced by scientific researchers for their peers on very similar topics to those of our corpus, could be presumed to share many features of the CP introductions. However, although the general rhetorical movement seemed very similar, the communicative context of the $\mathrm{CP}$, and the fact of it being spoken discourse led to difficulties in applying the complete CARS model. There were several moves encountered in the $\mathrm{CP}$ which were not specifically catered for in this written model, whilst other RA moves, such as that relating to the literature review, were far less elaborate. The order of moves posited by Swales also did not seem to reflect that found in the $\mathrm{CP}$.

24 As guidance therefore to analysing an oral genre, two other models ${ }^{3}$ of introductions in spoken academic genres were also consulted: Dubois' analysis of genre and structure in biomedical conference presentations (1980) and Thompson's analysis of introductions in university lectures (1994). These two models did indeed prove insightful for the analysis of our own oral data. The division established by Dubois between content orientation and listener orientation, provided a useful starting point for the dissection of the CP data. Likewise several categories identified by Thompson, such as those related to the metatextual function of 'Setting up the lecture framework' are also highly relevant to the $\mathrm{CP}$, as was the more flexible conception of move ordering. However, as Thompson's lecture data is didactic discourse, rather than that of research, 
with the audience being composed of novices and not peers, the communicative purpose is not the same. The 'funnel effect' or rhetorical narrowing characteristic of introductions in research process genres is absent. Dubois' analysis, being based on research presentations, could be expected to provide the greatest similarity with our own data. However Dubois' analysis is made within a tagmemic typology of narrative, and as a result is less applicable to the CP genre overall than the more purposeful rhetorical move analysis proposed by Swales. The fact that Dubois' analysis was based on a single scientific discipline, biomedicine, also meant that certain categories were too discipline-specific for a generic approach.

As none of the three models of article introductions analysed seemed entirely appropriate to our mixed-disciplinary $\mathrm{CP}$ corpus, we therefore decided to carry out a separate move analysis on our data. For all the move categories we took into account not only the speaker's monologue but also the information displayed on the visuals. The model proposed can be seen in figure 1 .

Figure 1. Proposed Move Model for scientific conference presentation Introductions

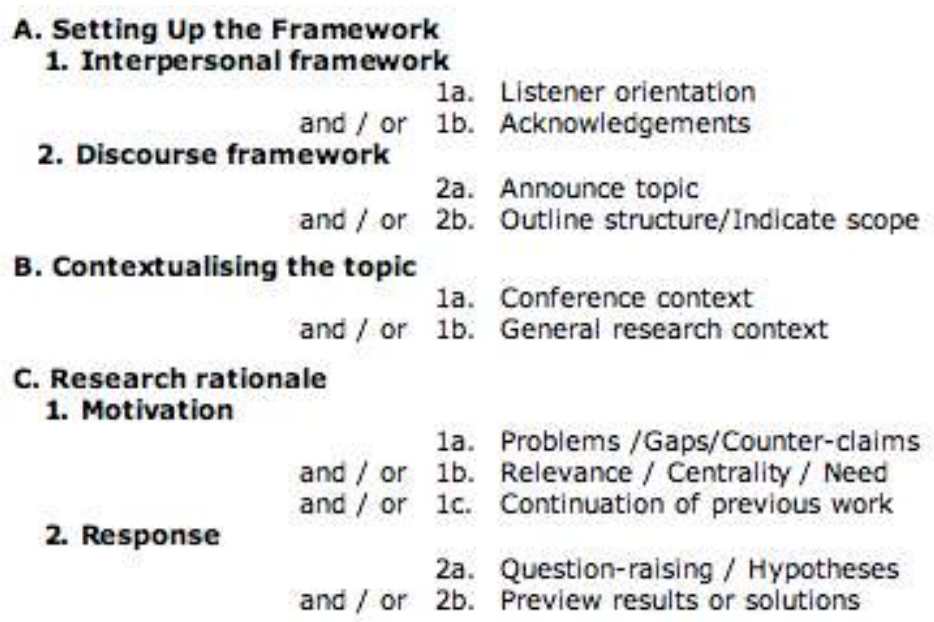

\section{Outline research goals}

\subsection{A proposed move model for the CP}

Move A, Setting up the framework, is where the divergences with the CARS model, designed for written academic discourse, are most apparent. The two main categories posited here, Interpersonal framework and Discourse framework, are very much motivated by the specific enunciative context of the CP: the presence of a live audience generates the need for a direct contact between the speaker and the audience, and cognitive constraints on the real-time processing of information also make it useful to give the audience explicit signalling of the topic and organisation of the talk. The Listener orientation step includes all remarks addressed by the speaker to the chairman, to the audience or the conference organisers, thanking them, greeting them and generally making contact. Acknowledgements, a category not present in the three models consulted, are placed at the end of the RA and PA, but occur at the beginning of the $\mathrm{CP}$ and include acknowledgements to collaborators, companies or funding agencies. As research in science is almost exclusively a collaborative effort, this is acknowledged by the individual speaker and can be seen as a politeness strategy. In the first of the two 
text-oriented components, the speaker Announces the topic of the presentation, either verbally and/or visually, foregrounding the particular presentation within the conference context. The Structure or scope step gives the audience some indication of how the talk is structured, and which aspects of the topic will be covered, to what degree of depth. The Outline Structure step also occurs within Swales' Move 3 (Occupy niche), but it seemed helpful to separate the textual moves from the more contentrelated moves, which are mixed together in the CARS model.

Once the framework (Move A) has been put into place, the two remaining moves identified for the $\mathrm{CP}$ are purely content oriented or ideational and broadly reflect Swales' rhetorical CARS structure. Within Move B, Contextualising the Topic, we have however also included a Conference context step. This includes references to other talks given at the conference concerned and generally precedes the General research context. The latter sub-move in fact conflates 'topic generalisations' and 'reviewing research' as identified in the CARS model, since distinguishing them in the CP context seemed particularly problematic. There would, moreover, seem to be no full-blown literature review such as found in research articles. Verbal references to published research in the $\mathrm{CP}$ are scarce, although there are a few scattered literature references on the visuals. This undoubtedly reflects the different epistemological function of the $\mathrm{CP}$ genre. What conference participants come to hear are results, and the novelty or news value has to be high; consequently the amount of time devoted to shared background knowledge is restricted.

Move C, Research rationale, the final move identified for the CP, collapses the Swalesian moves of Establish Niche and Occupy niche into one. In the more applied fields analysed within our corpus, in physics in particular but also to some extent in geology and medicine, scientists seem less concerned with carving out their particular research niche than with simply explaining the motivations or origins of the research project. Within the category of Motivation, we have therefore included the sub-move of Relevance/centrality/need, as by pointing out the importance of a research project, the scientist can also be seen to provide an explanation for why the research was undertaken. Other motivations for the research include the categories of Continuation, and that of signalling Gaps/problems and Counter-claims, categories also found within the CARS model. In several cases in our corpus, the problems or gaps evoked are followed by a Response, in the form of either Question raising or a Research hypothesis and even Previews of results or solutions. The culmination of the final move is often the description of the specific Research goal at the end of the introduction.

The linear representation presented in the above move model for the $\mathrm{CP}$ should not be considered as rigid. Positing a strict sequence of moves even for a genre as strictly codified as the RA can be problematic (cf. Samraj 2002). There is considerable flexibility due not only to disciplinary variation and the specific objectives of the research, but also because genres themselves are flexible and adapt in response to the evolving needs and practices of discourse communities (Askehave \& Swales 2001; Anthony 1999). This flexibility is even more apparent in presentations due to the real-time and sometimes impromptu decisions of the speaker, and because the rules are far less codified. The position of Outline structure/indicate scope would, for example, appear to be fairly flexible. References to the General research context can also occur not only within Move $\mathrm{B}$, but also later within Move $\mathrm{C}$, to reinforce the motivation for the research. Nor are the categories identified mutually exclusive. Some of the talks analysed contained the 
majority whilst others only very few. In a small number of talks we also found a certain amount of 'spillage', with elements of the Materials and Methods sections occurring within the Introductions. Overall however the linear sequence presented does reflect the moves in the majority of the CP analysed, and our initial findings would seem to indicate that the $\mathrm{CP}$ introduction, like the RA, has a clear rhetorical movement.

In order to verify these preliminary results it will be necessary to further refine the analysis proposed and also to consider the question of obligatory and optional moves within the CP. Our analysis, however, has shown that despite the complexity of the task, a rhetorical approach using move analysis can indeed be usefully applied to the CP. By laying the emphasis on communicative or rhetorical purpose, and on schematic structure, move analysis goes a long way towards teasing out some important generic features of the discourse. The fact that the conference presentation is not strictly codified in the same way as the RA means that giving a conference presentation can often be a considerable hurdle for novice and NNS presenters. As Shalom (2002) has pointed out, the introductions to the $\mathrm{CP}$ in particular often pose a serious problem for novices. The comparison with the structural organisation commonly found in the RA introductions has enabled us to pinpoint some striking differences between the two genres, and it is apparent that the written article cannot provide an adequate model. The importance of the interpersonal framework at the outset of the $\mathrm{CP}$ is a case in point and can undoubtedly provide a starting point for further pedagogical applications.

However, if move analysis of spoken academic genres has potential, it also has limitations. The move categories themselves are very slippery concepts. There is no one-to-one correspondence between linguistic signals and moves and sub-moves in the $\mathrm{CP}$ and applying the categories coherently therefore requires an efficient rating system and the participation of at minimum two raters. As already noted, these methodological difficulties are also compounded by the inherent flexibility of spoken discourse genres. More importantly, however, to the best of our knowledge, move analysis so far has not taken the multimodality of the discourse into account, and has been based solely on the linguistic realisation of the textual product. As became obvious, however when undertaking both the syntactic analysis and the move analysis, the multimodal dimension of the conference presentation cannot be ignored. The functions and frequencies of some syntactic structures within the $\mathrm{CP}$, such as inversion for example, can only be satisfactorily explained by the need to manage a multimodal text and to integrate information from different semiotics. Likewise some moves and section boundaries are signalled only via the visual channel, while other verbal information can only be correctly interpreted by reference to the visuals. To capture the defining features of a multimodal genre, such as the $\mathrm{CP}$, an analysis of the linguistic realisation can at best provide only a partial view. The third approach considered will thus tackle some of the issues involved in a multimodal analysis of the CP.

\section{Multimodal approach}

\subsection{Semiotic Modes}

A complete generic perspective on a discourse involves not only considering language, but also taking into account all the semiotic resources brought into play in the given 
discourse situation. Communication is rarely monomodal as meaning is created in many different ways in different communicative situations.

Figure 2. Parameters involved in multimodal analysis

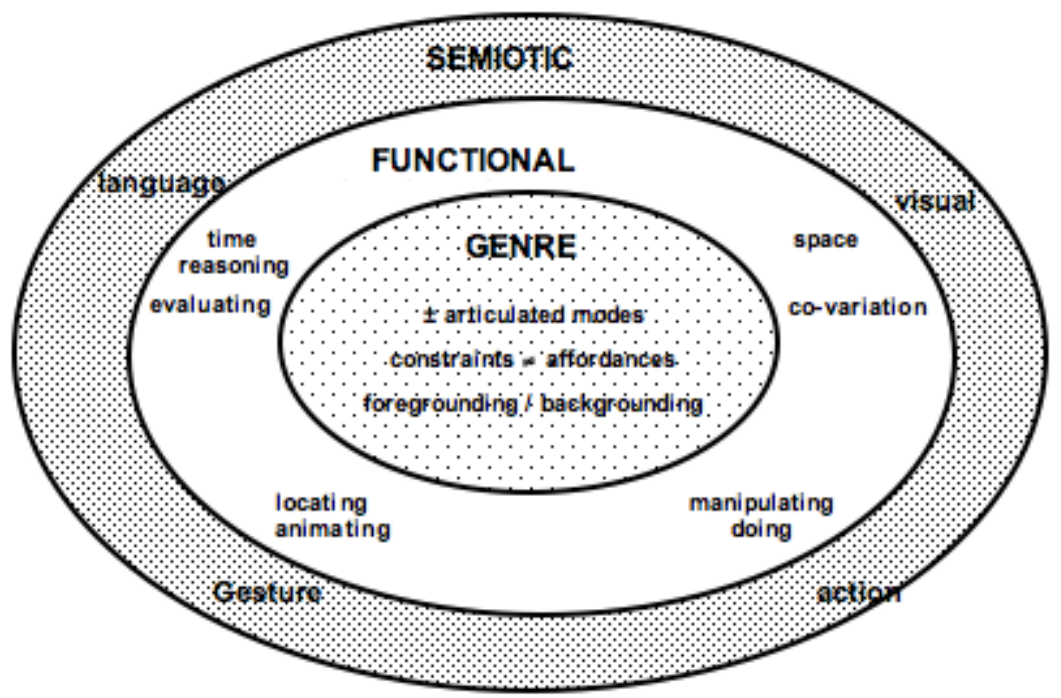

Figure 2 provides an overview of the different factors involved in a multimodal analysis. In scientific discourse genres four main semiotic modes can be used to communicate: language, visual communication, gesture and action. The importance of each, however, will vary according to the genre and communicative context. In the RA, for example, languages, both natural and formal, and visual communication will be the significant modes. Gesture and action will not be needed. In the laboratory or in the science classroom, in contrast, the four semiotic modes will come into play (Lynch \& Woolgar 1990; Kress et al, 2001).

In the $\mathrm{CP}$ three modes are used: language, visual communication and gesture. Language includes natural language, not only what the speaker says in his continuous commentary but also the written text on the slides, and formal languages mathematics or chemical symbols. The latter too can be either verbalised or written on the slides. In the $\mathrm{CP}$, the visual mode includes the use of transparencies, slides or PowerPoint displays and is a permanent accompaniment to the speaker's commentary. Gesture in the CPis much less fully articulated that the language or visual mode, and its use restricted mainly to the deictic function of pointing to and animating the visual display during the speaker's monologue, although it can have a wider range of functions during question time.Action is generally absent in the $\mathrm{CP}^{4}$.

\subsection{Functional Specialism}

Each of the four main semiotic modes outlined above has certain functional specialisms (Kress et al, 2001). Natural language, for example, whether speech or writing, is appropriate for the expression of time relations, whereas the visual mode is better adapted for expressing spatial relations. Language is more suited for evaluating, whereas visual communication in science is considerably more efficient at showing patterns, trends or co-variation of several parameters (Larkin \& Simon 1987; Krohn 
1991; Lemke 1998). Gesture is useful for locating items in the communicative context, or for animating a static visual. The importance of the visual mode, and the use of gesture, mean therefore that in the $\mathrm{CP}$ these different communicative functions can be distributed among the three modes. The conference speaker, unlike the RA writer, need not rely solely, or mainly, on language for certain functions.

\subsection{Generic Parameters}

Other factors that need to be taken into account in a multimodal approach to a genre are indicated in the inner circle of Figure 2. The degree of articulation of a specific mode, for example, will vary as a function of the communicative needs of a specific discourse community. In the community of deaf and dumb people gesture has developed into a highly articulated and grammaticalised mode. In scientific discourse communities, on the other hand, the visual mode is highly articulated, with different specialities having their own visual language. Audiences at scientific conferences have a very well-developed visual literacy, which enables them to 'read' the visual language of their specialism quickly and efficiently. Another factor to be taken into account as a specific genre unfolds is the relative foregrounding or backgrounding of the modes involved within the particular discourse. The interplay between the modes is not fixed but may shift in relative salience as the discourse progresses. In the RA and to some extent the $\mathrm{CP}$, the linguistic mode is dominant during the introduction, whereas in the results section, the visual mode is likely to gain more salience. Tracking such shifts as these is important for understanding how the complete discourse functions. In the case of the $\mathrm{CP}$ the dominance of the linguistic mode during the introduction can undoubtedly partly explain why novice researchers or NNS find this part of the presentation so problematic.

The precise material conditions of production and reception of a given genre also give rise to certain constraints and affordances or potentials which have a direct effect on the semiotic modes employed. In the case of the CP, both the constraints and affordances of the genre tend to enhance the communicative role of the visual mode. Among the constraints, a major one is related to the real-time delivery and interpretation of the discourse. The visual channel, however, allows faster mental processing and is particularly useful as already noted for explaining trends or displaying spatial information. It is therefore a highly efficient semiotic mode in this particular communicative situation. Another constraint concerns the often heterogeneous linguistic background of audiences at scientific conferences, which makes communication by language alone potentially unreliable. Visual communication in science is however universal, and communication via this mode is thus likely to be more effective for such audiences.

The particular affordances or potential linked to the CP environment likewise make visual communication a particularly prominent semiotic. There are, for example, few restrictions on the quantity or type of visuals shown. Visuals permanently accompany the speaker's monologue and much more information can thus be visualised in the CP than in an article. Such visualised information does not necessarily require verbalisation. In addition, specific visual strategies are also available for creating meaning in the $\mathrm{CP}$, and the grammar of visual composition can thus be fully exploited (Kress \& van Leeuwen 1996; Rowley-Jolivet 2002 and forthcoming). Many of the 
cohesive functions fulfilled by language in the article are accomplished by exploiting the semiotic possibilities of spatial, temporal, and spatio-temporal visual composition in the $\mathrm{CP}$. In certain disciplines such as geology, for example, a left-hand and righthand screen are often used which allows many logical relations (comparison/contrast, cause/consequence etc.) to be expressed visually by the juxtaposition of the two visuals. Similarly other visual strategies exist for communicating the structure of the talk and the links or parallelisms between different parts. Move categories, as already noted, can be communicated visually rather than solely by language: a change in type of visual, for example, can indicate a new move or sub-move.

While discovering the particular affordances of the visual semiotic in the CP genre remains for the moment a monomodal approach, it would nevertheless seem to be a necessary first step towards a fully multimodal approach. The latter is extremely complex and time-consuming, as it involves the simultaneous tracking of three modes and their interactions. The possible combinations are numerous as information can be carried by any of the three channels separately or by two or more simultaneously. The visual analysis alone therefore is far from providing a complete picture, but can nevertheless provide a methodological basis for teaching applications in oral scientific communication. Learners can be made more aware of the functional specialism of each semiotic mode, and be guided towards achieving an optimum fit between the type of information to be communicated and its semiotic expression.

\section{Conclusion}

The aim of this article was to provide a methodological overview of some of the issues involved in characterising the scientific conference presentation. The three types of analysis considered have all provided us with useful insights into certain aspects of the genre, although each also has its limitations, and leaves certain aspects unexplored.

41 The microscopic analysis of certain syntactic features provides new and useful information on the relation between generic characteristics and language choices at a local level - such as the contextual motivation for using pseudo-clefts but not passives in the CP. The emphasis on sentence level phenomena however does not allow investigation of the higher level structural organisation of the CP. Move analysis in contrast, which is a more macroscopic approach, does address the question of rhetorical structure, and our analysis of the $\mathrm{CP}$ introductions has shown considerable differences between the $\mathrm{CP}$ and the RA in this respect and would also seem to hold considerable potential for analyses of a more pedagogical type.

However, neither the move analysis nor the syntactic analysis make it possible to adequately capture the multimodal dimension, which clearly differentiates the $\mathrm{CP}$ from a corresponding article. In the $\mathrm{CP}$ the visual semiotic plays an essential role. As a first step therefore we have tried to see exactly what the affordances of the visual mode in the $\mathrm{CP}$ genre are, and to gauge how its communicative potential is enhanced compared to the visuals of the RA. Any method that neglects the vital multimodal nature of the conference presentation in science will necessarily only present a partial view of the genre. In order to fully characterise the genre it will be necessary to combine the different elements and approaches examined. This however remains a formidable task. 


\section{BIBLIOGRAPHY}

Anthony, L. 1999. "Writing research article introductions in software engineering: How accurate is a standard model?" IEEE Transactions on Professional Communication 42/1, 38-46.

Askehave, I. \& J.M. Swales. 2001. “Genre identification and communicative purpose: A problem and a possible solution". Applied Linguistics 22/2, 195-212.

Brett, P. 1994. "A genre analysis of the results section of sociology articles". English for Specific Purposes 13/1, 47-59.

Candlin, C.N. \& K. Hyland (eds.) 1999. Writing: Texts, processes and practices. London: Longman. Carter-Thomas, S. \& E. Rowley-Jolivet. 2001. "Syntactic differences in oral and written scientific discourse: the role of information structure". ASp 31-33, 19-37.

Dubois, B. 1980. "Genre and structure of biomedical speeches". Forum Linguisticum Vol. V, 140-168. Dudley-Evans, T. 1994. “Genre analysis an approach to text analysis for ESP”. In Coulthard M. (ed.), Advances in Written Text Analysis. London: Routledge, 219-228.

Fairclough, N. 1992. Discourse and Social Change. London: Polity.

Hopkins, A. "An Investigation into the organizing and organizational features of published conference papers", Unpublished MA Dissertation, University of Birmingham.

Hyland, K. 2000. Disciplinary Discourses. Social interactions in academic writing. London: Longman.

Kress, G. \& T. van Leeuwen. 1996. Reading Images. The grammar of visual design. London: Routledge.

Kress, G., C. Jewitt, J. Ogborn \& C. Tsatsarelis. 2001. Multimodal Teaching and Learning. The rhetorics of the science classroom. London: Continuum.

Krohn, R. 1991. “Why are graphs so central in science?”. Biology and Philosophy 6, 181-203.

Larkin, J.H. \& H.A. Simon. 1987. "Why a diagram is (sometimes) worth ten thousand words". Cognitive Science 11, 65-99.

Lemke, J. 1998. "Multiplying meaning: Visual and verbal semiotics in scientific text". In Martin J.R. \& R. Veel. Reading Science. Critical and functional perspectives on discourses of science. London: Routledge.

Lynch, M. \& S. Woolgar (eds.) 1990. Representation in Scientific Practice. Cambridge: MIT Press.

Nwogu, K. 1997. “The medical research paper: Structure and functions”. English for Specific Purposes 16/2, 119-138.

Peng, J. 1987. “Organisational features in chemical engineering research articles”. ELR Journal 1, 79-116.

Rowley-Jolivet, E. 1999. "The pivotal role of conference papers in the network of scientific communication". ASp 23-26, 179-196.

Rowley-Jolivet, E. 2002. "Visual discourse in scientific conference papers. A genre-based study". English for Specific Purposes 21/1, 19-40.

Rowley-Jolivet, E. Forthcoming. "Different visions, different visuals. A social semiotic analysis of field-specific visual composition in scientific conference presentations". Visual Communication, Sage. 
Rowley-Jolivet, E. \& S. Carter-Thomas. Forthcoming. "Genre awareness and rhetorical appropriacy: manipulation of information structure by NS and NNS scientists in the international conference setting." English for Specific Purposes, Elsevier.

Samraj, B. 2002. "Introductions in research articles: variations across disciplines". English for Specific Purposes 21/1, 1-17.

Shalom, C. 2002. "The academic conference: A forum for enacting genre knowledge”. In Ventola E. et al., The Language of Conferencing. Frankfurt am Main: Peter Lang, 51-68.

Simpson, R.C. \& Swales, J.M. (eds.) 2001. Corpus Linguistics in North America. Ann Arbor: University of Michigan Press.

Swales, J. 1981. Aspects of article introduction., Birmingham; UK: The University of Aston, Language Studies Unit.

Swales, J. 1990. Genre Analysis: English in academic and research settings. Cambridge: Cambridge University Press.

Swales, J. In press. Research genres: Explorations and applications. New York: Cambridge University Press.

Thompson, S. E. 1994. "Frameworks and contexts: A Genre-based approach to analysing lecture introductions". English for Specific Purposes 13/2, 171-186.

Thompson, S. E. 2003. "Text-structuring metadiscourse, intonation and the signalling of organisation in academic lectures". Journal of English for Academic Purposes 2, 5-20.

Trosborg, A. (ed.) 2000. Analysing Professional Genres. Amsterdam: John Benjamins.

Ventola, E., C. Shalom \& S. Thompson (eds). 2002. The Language of Conferencing. Frankfurt am Main: Peter Lang.

\section{APPENDIXES}

\section{Appendix 1: The Corpus}

The spoken data used in this study comprise 44 oral presentations given by NS at the following conferences:

1. EUG VII : European Union of Geosciences, 4-8 April 1993, Strasbourg.

2. International Symposium on Mineralization related to Mafic and Ultramafic Rocks, 1-3 Sept. 1993, Orleans.

3. First International Symposium on Conservative Treatment in Oncology, 17-19 June 1993, Lyon.

4. First Annual European-American Conference on Gastrointestinal Oncology: Cancers of the Lower Gastrointestinal Tract, 22-24 Sept. 1994, Bordeaux.

5. Euro Electromagnetics. International Symposium on Electromagnetic Environments and Consequences. May 30 - June 4, 1994, Bordeaux.

6. $15^{\text {th }}$ International Symposium on Plasma Chemistry (ISPC 15). Orléans, 9-13 July 2001.

The comparative corpus of 9 presentations $(\mathrm{P})+9$ proceedings articles $(\mathrm{A})$ in physics (Conference $\mathrm{N}^{\circ} 5$ above) comprises the following: 


\begin{tabular}{|c|c|}
\hline A2 - P2 & Sandia National Laboratories' high power electromagnetic impulse sources \\
\hline A3 - P3 & Stacked Blumlein pulse generators: versatile sources of high power repetitive waveforms \\
\hline A4 - P4 & High voltage pulse sharpening using nonlinear ferroelectric ceramic dielectrics \\
\hline A5 - P5 & Lightweight, tactical prime power for mobile pulsed power applications \\
\hline A9 - P9 & The development of high peak power solid state pulse generators \\
\hline $\begin{array}{l}\text { A11 - } \\
\text { P11 }\end{array}$ & Milo experiments and computer simulations \\
\hline $\begin{array}{l}\text { A13- } \\
\text { P13 }\end{array}$ & Low-voltage, explosive whisker emission cathode studies \\
\hline $\begin{array}{l}\text { A14- } \\
\text { P14 }\end{array}$ & $\begin{array}{l}\text { Efficiency enhancement of high power vacuum backward-wave oscillators driven by } \\
\text { short pulse and long pulse electron beams }\end{array}$ \\
\hline $\begin{array}{l}\text { A15- } \\
\text { P15 }\end{array}$ & Nonlinear space-charge waves in an axially uniform waveguiding structure \\
\hline
\end{tabular}

Appendix 2: Three Models of Introductions in Academic genres

\begin{tabular}{|c|c|c|c|c|c|}
\hline \multicolumn{2}{|r|}{$\begin{array}{l}\text { SWALES }(1990) \\
\text { Research Articles }\end{array}$} & \multicolumn{2}{|c|}{$\begin{array}{l}\text { DUBOIS }(1980) \\
\text { Biomedical CPs }\end{array}$} & \multicolumn{2}{|r|}{$\begin{array}{c}\text { THOMPSON (1994) } \\
\text { Lectures }\end{array}$} \\
\hline & & \multicolumn{2}{|c|}{ A. Listener orientation } & \multicolumn{2}{|c|}{$\begin{array}{l}\text { Function 1: Set Up } \\
\text { Lecture Framework }\end{array}$} \\
\hline & & 1 & To Chairperson & SubF1 & Announce topic \\
\hline & & 2 & To audience & SubF2 & Indicate scope \\
\hline & & 3 & To projectionist & SubF3 & Outline structure \\
\hline & & & & SubF4 & Present aims \\
\hline \multicolumn{2}{|c|}{ Move 1: Establishing a territory } & \multicolumn{2}{|c|}{ B. Content orientation } & \multicolumn{2}{|c|}{ Function 2: Put Topic in Context } \\
\hline Step 1 & Claim centrality & 1 & Non-technical & SubF1 & $\begin{array}{l}\text { Show importance/ } \\
\text { relevance of topic }\end{array}$ \\
\hline Step 2 & Make topic generalizations & 2 & Technical & SubF2 & Relate 'new' to 'given' \\
\hline Step 3 & Review previous research & 2a & $\begin{array}{l}\text { Subject } \\
\text { qualification }\end{array}$ & SubF3 & Refer to earlier lectures \\
\hline \multicolumn{2}{|c|}{ Move 2: Establish a Niche } & $2 b$ & Amplification & & \\
\hline St. 1a & Counter-claim & $2 c$ & Pre-hypothesis & & \\
\hline $1 \mathrm{~b}$ & Indicate gap & $2 d$ & Hypothesis & & \\
\hline $1 \mathrm{c}$ & Question-raising & $2 d^{*}$ & Implications & & \\
\hline 1d & Continue tradition & & & & \\
\hline \multicolumn{2}{|c|}{ Move 3: Occupy the Niche } & & & & \\
\hline St. 1a & Outline purposes & & & & \\
\hline $1 \mathrm{~b}$ & $\begin{array}{l}\text { Announce present } \\
\text { research }\end{array}$ & & & & \\
\hline 2 & Announce man findings & & & & \\
\hline 3 & Indicate RA structure & & & & \\
\hline
\end{tabular}

\section{NOTES}

1. Details of the conferences, presentations and articles can be found in Appendix 1. 
2. Examples from the proceedings articles are referred to by the letter A followed by the number of the article, and examples from the conference presentations by the letter P (see Appendix 1).

3. All three models - Swales (1990), Dubois (1980) and Thompson (1994) - are reproduced in Appendix 2.

4. An interesting exception to this, however, is modelling or simulation papers in science in which the speaker runs the simulation or 'virtual experiment' on his laptop in front of the audience.

\section{ABSTRACTS}

This article will consider three different approaches to a genre analysis of the conference presentation (CP) in science. We highlight some of the research problems involved in such an investigation and discuss the advantages and limitations of the three methods in furthering our understanding of this important spoken academic genre. The first approach is based on a microscopic view of the discourse and focuses on certain recurrent syntactic features of the CP that are pragmatically motivated by the communicative context. The second approach is more macroscopic, and discusses the feasibility of using move analysis as means to exploring the rhetorical organisation of the introduction section of the CP. However as neither of these approaches addresses the vital multimodal nature of the $\mathrm{CP}$, we therefore underline in the third part some of the important features involved in a multimodal analysis.

Cet article envisage trois démarches différentes pour la caractérisation d'un genre scientifique spécifique : la communication orale de congrès. Nous mettons en évidence certains problèmes méthodologiques soulevés par une telle analyse, et nous traitons des avantages et des inconvénients des trois démarches pour appréhender ce genre scientifique important. La première démarche se fonde sur une analyse microscopique du discours et s'attache à l'étude de certaines particularités syntaxiques de la communication scientifique orale qui résultent des motivations particulières $d u$ contexte communicatif $d u$ congrès scientifique. La deuxième démarche est macroscopique : il s'agit d'explorer les possibilités d'analyser l'organisation rhétorique de la communication de congrès à l'aide d'un move analysis. Toutefois, ces deux démarches n'éclairent pas la dimension multimodale de la communication orale de congrès. Nous soulignons donc dans une troisième partie certains aspects importants d'une analyse véritablement multimodale.

\section{INDEX}

Keywords: genre, move analysis, multimodality, rhetoric, conference presentation, syntax Mots-clés: communication de congrès, genre, move analysis, multimodalité, rhétorique, syntaxe 


\section{AUTHORS}

\section{SHIRLEY CARTER-THOMAS}

Shirley Carter-Thomasestmaître de conférences à l'Institut National des Télécommunications (GET/INT), Évry. Ses domaines d'intérêt sont l'analyse du discours scientifique et le passage de l'oral à l'écrit, la pragmatique et la syntaxe. Elle est membre du groupe de recherche OSTERLITS (UMR 7108) du CNRS. shirley.thomas@it-sudparis.eu

\section{ELIZABETH ROWLEY-JOLIVET}

Elizabeth Rowley-Jolivet est maitre de conférences à l'Institut Polytechnique de l'Université d'Orléans. Ses axes de recherche sont l'analyse du discours scientifique oral, la communication visuelle et la sociologie de la science. Elle est membre du groupe de recherche OSTERLITS (UMR 7108) du CNRS. Elizabeth.Jolivet@univ-orleans.fr 